\title{
Study Noise Effects on The Students of The Faculty of Engineering/ Mustansiriyah University
}

\author{
Shatha Abduljabbar Ibrahim \\ Environmental Eng. Dep. \\ Al-Mustansiriyah University, Baghdad, IRAQ \\ dr.shathaaj@uomustansiriyah.edu.iq \\ Received: 27-02-2017 Revised: 04-07-2017 Accepted: 18-Dec.-2017 \\ http://doi.org/10.29194/NJES21020177
}

\begin{abstract}
Noise effects on the students include both auditory and non-auditory effects and cause the lack of concentration and disability of learning and communication. The Faculty of Engineering was chosen to conduct the questionnaire because the students have both theoretical and practical courses and they spend one-third of their day in the laboratories, so it is expected they exposure to noise more than other faculties' students A questionnaire was conducted to understand the effect of noise on student behavior and whether they could classify the sounds that they heard as noise and determine the noise sources (indoor, outdoor) and the noisiest places (classroom, laboratory, and campus). 438 students participated in this questionnaire from all stages, and they covered eight engineering departments in the Faculty of Engineering, Mustansiriyah University. A statistical analysis of the questionnaire found that $39.5 \%, 46 \%, 32 \%$ and $49 \%$ of students suffered from noise in classrooms, laboratories, open spaces and closed spaces (campus), respectively. In the actual situation, the effects that students experience can be arranged in the following descending order: feeling discomfort, hearing difficulty, raising the voice when speaking, lack of concentration, headache, tinnitus and nausea. Using a sound and vibration meter with the analyzer, the noise levels in $\mathrm{dBA}$ were measured in the noisiest places that the students mentioned. The noise levels exceed the standard limitation that organizations and agencies such as the WHO determined.
\end{abstract}

Keywords: Noise effects, Questionnaire, Faculty of Engineering, Students.

\section{Introduction}

Noise is classified as a major second pollutant after air pollution with dangerous effects on human health and activities by the World Health Organization (WHO) [1]. These dangerous effects come from the interference of noise with all human activities, such as speaking, learning, working, transportation, sleeping, entertainment, during the day and at night at work and at home.
The noise levels may exceed the acceptance levels by organizations and agencies such as the WHO, OSHA, and NIOSH [1-3].

The diverse effects of noise include both human auditory health effects and non-auditory health effects such as anxiety, discomfort, nervousness, and frenzy. Noise can also cause nausea, headaches and physical diseases such as high blood pressure and cardiovascular disease [4 - 6]. Researchers study the noise sources, noise levels and the effects of noise on students in various educational institutions, and they found adverse effects of noise on the students' concentration, ability of learning, communication and continuity with teachers [7 - 9].

Noise questionnaire are used in the studies to cover a wide range of the population (number, age, career) in specific area and communities and relate the noise exposures, noise sensitivity and effects of noise on subjective health $[10,11]$. As part of health surveillance, some universities resort to the questionnaire to determine the noise sources, levels, and places and study the auditory and non-auditory effects of noise on students' health by allocating specific pages about noise on its official website such as the University of California and the University of Nottingham $[12,13]$.

In this study, a questionnaire was used to understand the opinions and perceptions of students about noise (sources, levels and effects). We used a statistical analysis to understanding the answers and measured the noise levels in the places where students mentioned to have high noise levels to relate between their answers and the actual situation.

\section{Materials and Methods}

\subsection{Study Area}

In total, 438 students participated in the questionnaire from all stages, and they covered eight engineering departments (Civil, Electrical, Mechanical, Environmental, Computer and Software, Transportation and Highway, Material, and Architectural) in the Faculty of Engineering, Mustansiriyah University, 
Baghdad. Figure 1 shows a satellite image of the faculty site.



Figure 1: Satellite image of the Faculty of

Engineering site in Bab Al-Moatham districtBaghdad

\subsection{Questionnaire}

The questionnaire was designed to fit the education background, study stage and daily study or the students. The age of the targeted sample was 18 to 25 years old of both genders. The goals of the questionnaire are detecting the noise sources in the classrooms, labs, campus, student club, reading room central and copier shops; showing the negative effects of noise that the students may feel, such as hearing difficulty, lack of concentration, raising the voice when speaking, feelings of discomfort, tinnitus, headache and nausea; and determining the student knowledge of noise and their opinions. The questionnaire details illustrated in Table 1.

\subsection{Statistical Analysis}

Likert scale was used to measure the frequencies with five categories (1) strongly disagree, 2) disagree, 3) neutral, 4) agree, and 5) strongly agree) for specific noise questions and two categories (1) yes and 2) no) for general noise questions. The results were analyzed using the Statistical Package for the Social Sciences (SPSS) software version 16.

\subsection{Measurement Methodology}

The statistical analysis of the questionnaire located the noisiest places that the participating students mentioned. Then, we measured the noise levels in most of these places and related the answers of the participants and the measurements. These measurements were performed using SVAN957 Type 1 sound and a vibration meter with an analyzer according to ISO1996-1 [14]. Figure 2 shows the noise measurement results in the faculty campus.

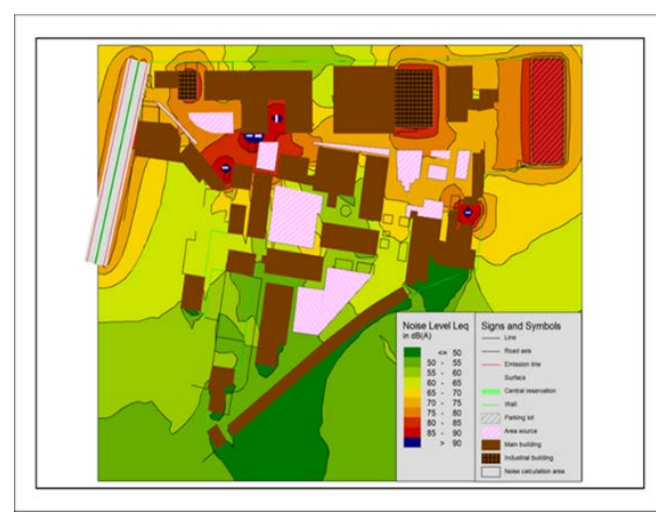

Figure 2: Noise measurement results in the faculty campus.

\section{Result and Discussion}

\subsection{Noise Sources Inside Building Department \\ 3.1.1 Classroom}

Generally, $39.5 \%$ of students from all departments suffer from noise in the classroom. There are two types of noise sources in the classroom: indoor and outdoor. Indoor noise comes from air conditioner devices, whereas outdoor noise comes from students' voices when they gather in the squares, electric diesel generators, horn vehicles, traffic and the parking lots at the nearby boundaries of the campus.

A total of $12.8 \%$ the noise originates from electric generators, particularly in the hot seasons, when the classroom windows are opened while the electric generators are working.

The background noise levels were measured in an unoccupied classroom for all departments and approached $50 \mathrm{~dB}$, which is higher than the acceptable background noise level of $35 \mathrm{dBA}$ [15, 16]. Figure 3 shows the questionnaire results (classroom noise) for all departments.

\section{Laboratories 3.1.2}

All departments except the architectural department have laboratories in their schedule. The students spend one-third of their time in the working day in the labs, and $46 \%$ of students suffer from lab noise. The student mentioned that the dominant noise in the labs originated from multiple devices in the Hydraulic, Structure, Concrete, Workshops, Electronics, Sanitary, Thermodynamics, Metal Inspection, Chemical and Polymers labs. According to the laboratory safety design guide [17], the noise levels at laboratory benches should not exceed 55 $\mathrm{dBA}$, but the actual noise levels in these labs approach 110 dBA [18].

The students who participated in the questionnaire stated that the written and oral occupational health and safety instructions are negligible noise pollution risks and how to address them. Safety equipment such as ear 
protectors and earmuffs are not available in the labs. In addition, there is no warning sign in the zones with high noise levels.

Figure 4 shows the questionnaire results of the labs noise for all departments.

\subsection{Noise Sources in Faculty Campus \\ 3.2.1 Open Spaces (Squares and Gardens)}

Thirty-two percent of students are exposed to the noise of students gathering in squares and gardens, where the measured noise levels approach $75 \mathrm{dBA}$. In addition, 26\% of students are exposed to high noise levels from five electrical diesel generators with power $500 \mathrm{kVA}$, which are distributed in these areas; the measured noise levels near the generators when they are turned on approach $90 \mathrm{dBA}$. The squares, gardens and corridors where students gather constitute approximately one-fifth of the campus. Thus, 58\% of the students did not find the necessary comfort and relaxation in this small area.

\subsubsection{Closed Spaces (Student Club, Reading Room Central, Copier Shops) \\ The main noise source in the student club is the} music, which emits a noise level of $90 \mathrm{dBA}$. In total, $49 \%$ of the students who participated in the questionnaire complained about this loud music

The atmosphere of the reading room central is relatively quiet; the noise levels did not exceed 50 dBA. The complaints of noise for $12 \%$ of the students originated from the excessive movements for some students and their high voice.

Copier shops have an area of approximately 5 $\mathrm{m} 2$ with 3-4 copy machines. The students who gather in this area create a noisy ambience, and $6 \%$ of them complained of the noise.

Figure 5 shows the percentage of students who are affected by noise sources on campus.

\subsection{Noise Effects of which the Students Complain}

The most common effects of several hours of noise exposure per day include auditory effects such as temporary and primary threshold shift and non-auditory effects such as high blood pressure, hearing difficulty, and lack of concentration. The effects that students experience can be arranged in the following descending order: feeling of discomfort, hearing difficulty, raising the voice when speaking, lack of concentration, headache, tinnitus and nausea. Figure 6 shows the student percentage of complaints from these effects.

\subsection{General Question about Noise}

General noise-related questions were posed to the participating students to determine their knowledge about noise. The results are as follows: $49 \%$ of the students focused on their knowledge about noise and its effects during their study, whereas $51 \%$ of the students mentioned the sources of their knowledge, which included TV scientific reports, seminars, conferences and unsystematic books.

For the questions about the students' opinions regarding the necessity of providing guidance for occupational health and safety in the laboratory, wearing ear protectors and earmuffs, and using sound insulation in classrooms and laboratories, the "agree" answers were 82\%, 52\% and 83\%, respectively.

\subsection{Neutral Answers}

Statically, the researchers found that neutral answers indicated that the respondents did not know the answers of whether they agree or disagree with the questions [19-21]. In this study, up to $25 \%$ of the answers of the students were neutral answers to all questions of all topics. However, in acoustical science, from multiple noise definitions, noise is defined as unwanted sound and is a subjective sensation [22-24]; someone can feel discomfort from the sound of a vehicle horn, and another may not. Thus, the neutral answers indicate that the respondents did not know whether the sounds that they heard were classified as noise. There are several reasons: first, the continued power outages across the country induces the use of different types of electricity generators, which emit noise levels of 80-100 dBA during the day and at night; second, traffic noise on the main roads during the day approaches $75 \mathrm{dBA}$; third, the residential area became mixed with industrial, commercial areas. These reasons increase the noise levels in the residential area during the day and at night above the standard limitations of $50 \mathrm{dBA}$ during the day and $45 \mathrm{dBA}$ at night [25]. Thus, the respondents who are exposed to noise levels higher than the limitations during their day and night and accordingly the above noise definitions do not distinguish whether the sounds that they heard can be classified as noise, and they do not know the boundaries between the sound and noise.

\footnotetext{
.4Conclusions

This study found that approximately $75 \%$ of the participating students in the questionnaire could recognize whether the sound heard was noise, and the remaining answers were neutral. From previous studies and field-measuring noise levels, the noise levels exceed the limitations that organizations and agencies such as the WHO, OSHA and NIOSH approved in classrooms, laboratories and faculty campus.
} 
In future studies, a health survey with the measured noise levels is recommended plus publishing the results achieved in this field in the universities sites and social networking sites to extend for community benefit.

\section{Acknowledgments}

The author would like to thank Mustansiriyah University(www.uomustansiryah.edu.iq) Baghdad -Iraq for its support in the present work.

\section{References}

[1] WHO regional officer for Europe, "JRC Eureapon Commission Burden of Disease from Environmental Noise, Quantification of Healthy Life Years Lost in Europe”, World Health Organization, 2011.

[2] US Occupational Health and Safety Administration (OSHA), 29 CFR1910.5

[3] National Institute for Occupational Safety and Health (NIOSH), “Criteria for a Recommended Standard, Occupational Noise Exposure”, NIOSH Publication No.98-126.

[4] Canadian Centre for Occupational Health and Safety (CCOHS),"Noise-Auditory Effects", 2011.

[5] A. Stansfeld, M. Matheson, "Noise Pollution: Non-Auditory Effects on Health" , British Medical Bulletin,68, 243-257, 2003.

[6] L. Kinsler, A.Frey, A.Coppens, J.Sanders, "Fundamentals of Acoustics", $4^{\text {th }}$ edition, John Wiley \&Sons,Inc, 2000.

[7] M. El-Sharkawy, A. Alsubaie, “ Study of Environmental Noise Pollution in the University of Dammam Campus”, Saudi Journal of Medicine \&Medical Sciences,2, 3, 178-184,2014.

[8] S. Ozer, M. Zengin, H. Yilmaz, "Determination of the Noise Pollution on University (Education) Campuses: a Case Study of Ataturk University), Ekologi, 23, 90, 49-54.2014,

[9]B.Phukan, K.Kalita, “An Experimental Study of Noise Pollution in Guwahati, Assam, India”, International Journal of Environmental Sciences ,3, 5,2013.

[10] H. Kishikawa, T., Matsui, I., Uchiyama, M., Miyakawa, K., Hiramtsu, A.Stansfels, "Noise Sensitivity and Subjective Health: Questionnaire Study Conducted along Trunk Roads in Kusatsu, Japan” , Journal of Noise \&Health, vol.11, Issue.43, pp.111-117,2009.

[11] Th. Clausen, K. Christensen, Th. Lund, J. Kristiansen, "Self-Reported Noise Exposure as a Risk Factor for Long-Term Sickness
Absence”, Journal of Noise \&Health, vol.11, Issue.43,pp. 93-97,2009.

[12] https://www.uhs.berkeley.edu

[13]

https://www.nottingham.ac.uk/safety/policie s-and-guidance/noise/noise.aspx

[14] ISO1996-1, “Acoustics-Description and Measurement of Environmental Noise, Part 1: Basic Quantities and Procedures”..1996,

[15] American National Standard (ANSI S12.602002), "Acoustical Performance Criteria, Design Requirements, and Guidelines for Schools”, Accredited Standards Committee S12, Noise, Acoustical Society of America,2002.

[16] Schallschutz im Hochbau Anforderungen und Nachweise, "Sound Insulation in Buildings Requirements and Testing”, DIN4109:1989-11, 1989.

[17] Environmental Health and Safety Department, "Laboratory Safety Design Guide-General Requirements for Laboratories", University of Washington.2005,

[18] Sh. Ibrahim," Determining Noise Zones in the Laboratories of the College of Engineering at the University of AlMustansiriyah”, International Journal of Emerging Science and Engineering (IJESE), 2 ,9,2014.

[19] D. Ducharme,D.,“ Survey Response Categories: Guide for Using Neutral or N/A Options”, War Gaming Department, U.S. Naval War College,2016.

[20] StatPac Inc,“ The "Don't Know", "Undecided",\&"Neutral"Response Options”, StatPac. Inc.,2014.

[21] E. Powell, (2009), “ Ways to Word Answer Choices in Questionnaires”, Board of Regents of the University of Wisconsin System, doing business as the Division of Cooperative Extension of the University of Wisconsin-Extension.,2009.

[22]R. Peters, B. Smith, M. Hollins, "Acoustics and Noise Control”, $3^{\text {rd }}$ edition, Pearson Education Limited..2011,

.I [23] Ver, L. Beranek, L.,“ Noise and Vibration Control Engineering”, $2^{\text {nd }}$ edition, John Wiley \&Sons, Inc.2006,

[24].L Wang, N. Pereira, Y. Hung,“ Hand Book of Environmental Engineering, Advanced Air and Noise Pollution Control”, 2, Humana Press,2005.

.B [25]Birglund, T. Lindvall, D. Schwela “Guidelines for Community Noise”, WHO Publications..1999, 


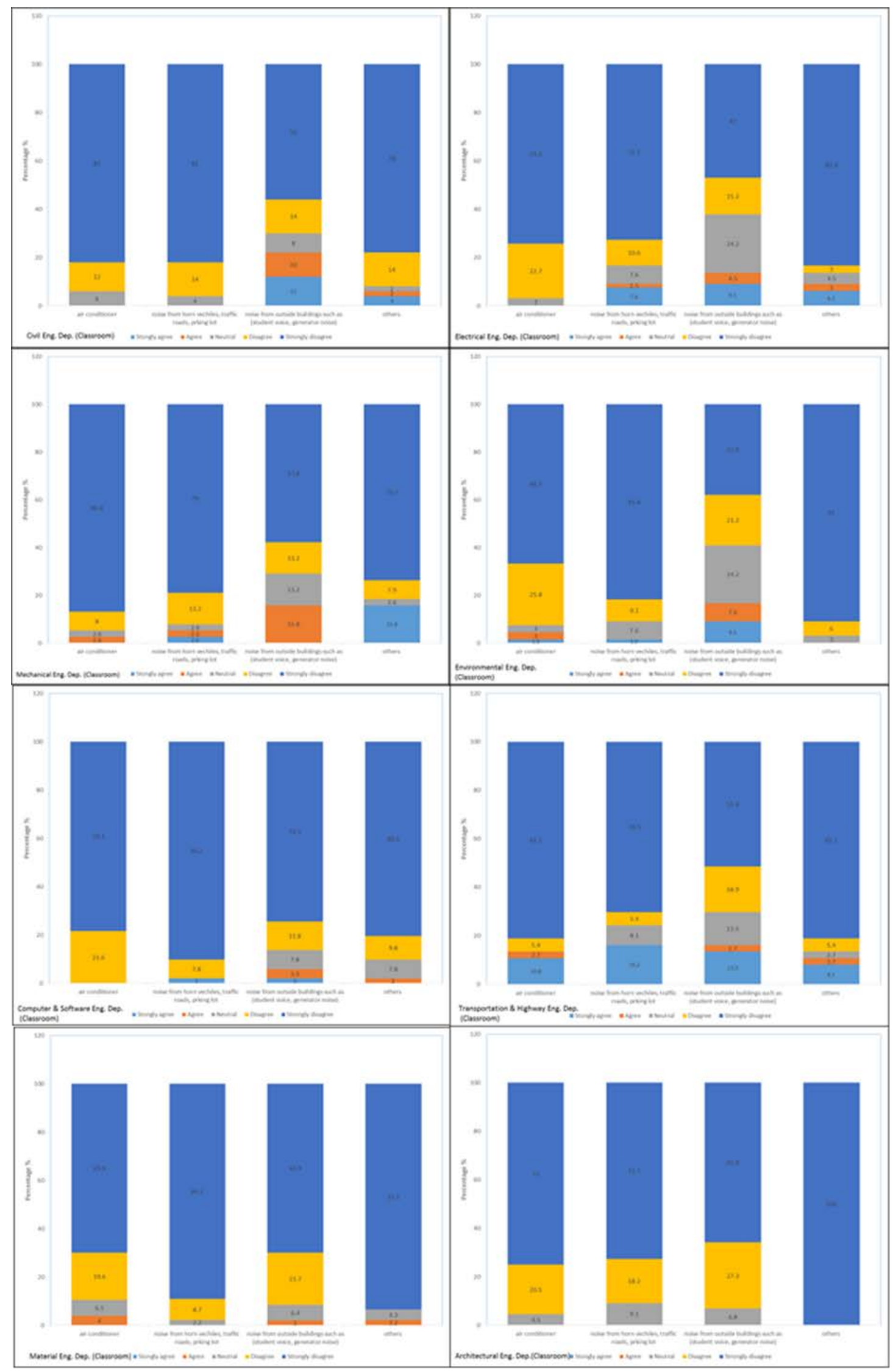

Figure 3: Questionnaire results of classroom noise for all departments 


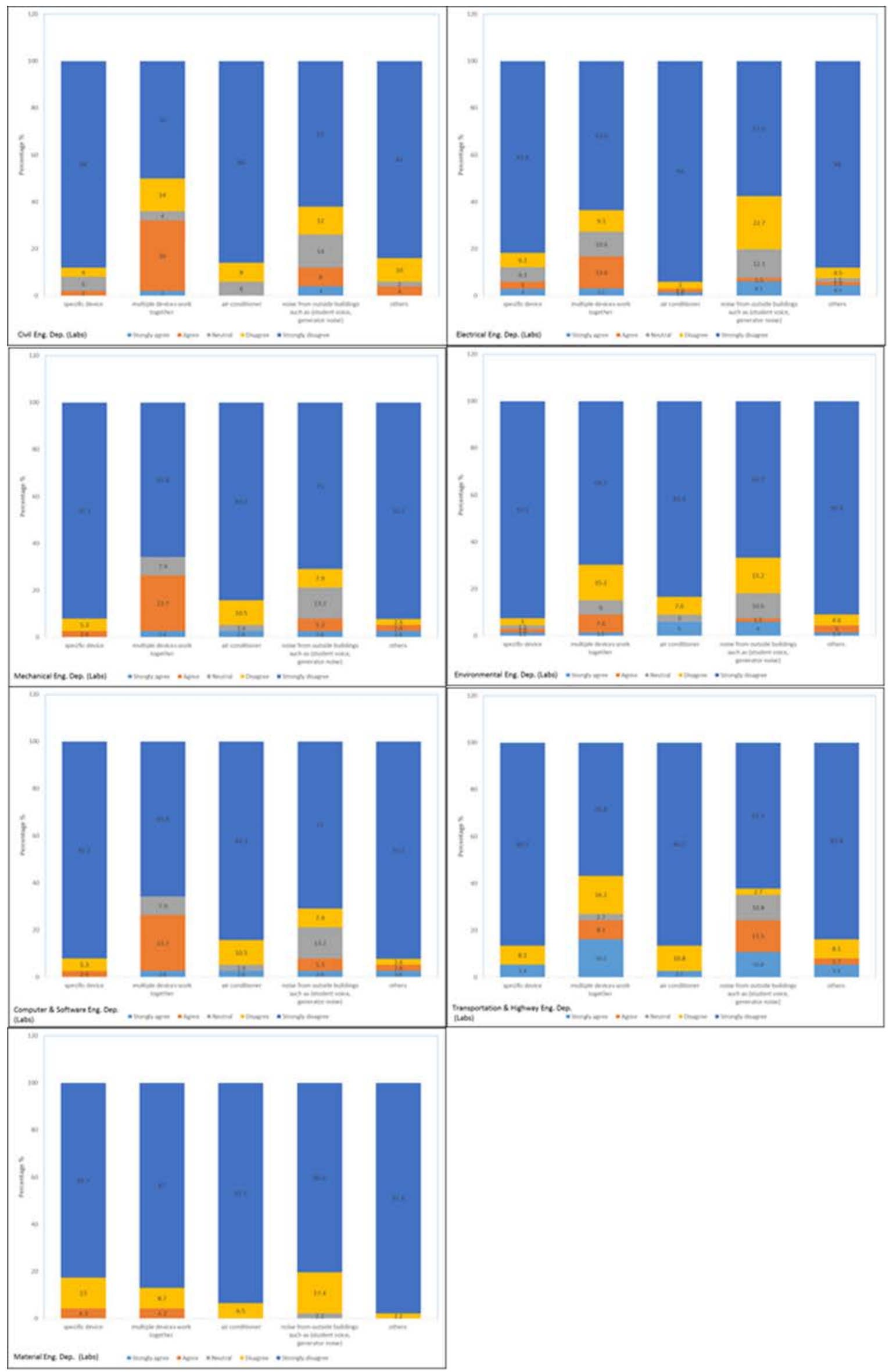

Figure 4: Questionnaire results of labs noise for all departments 


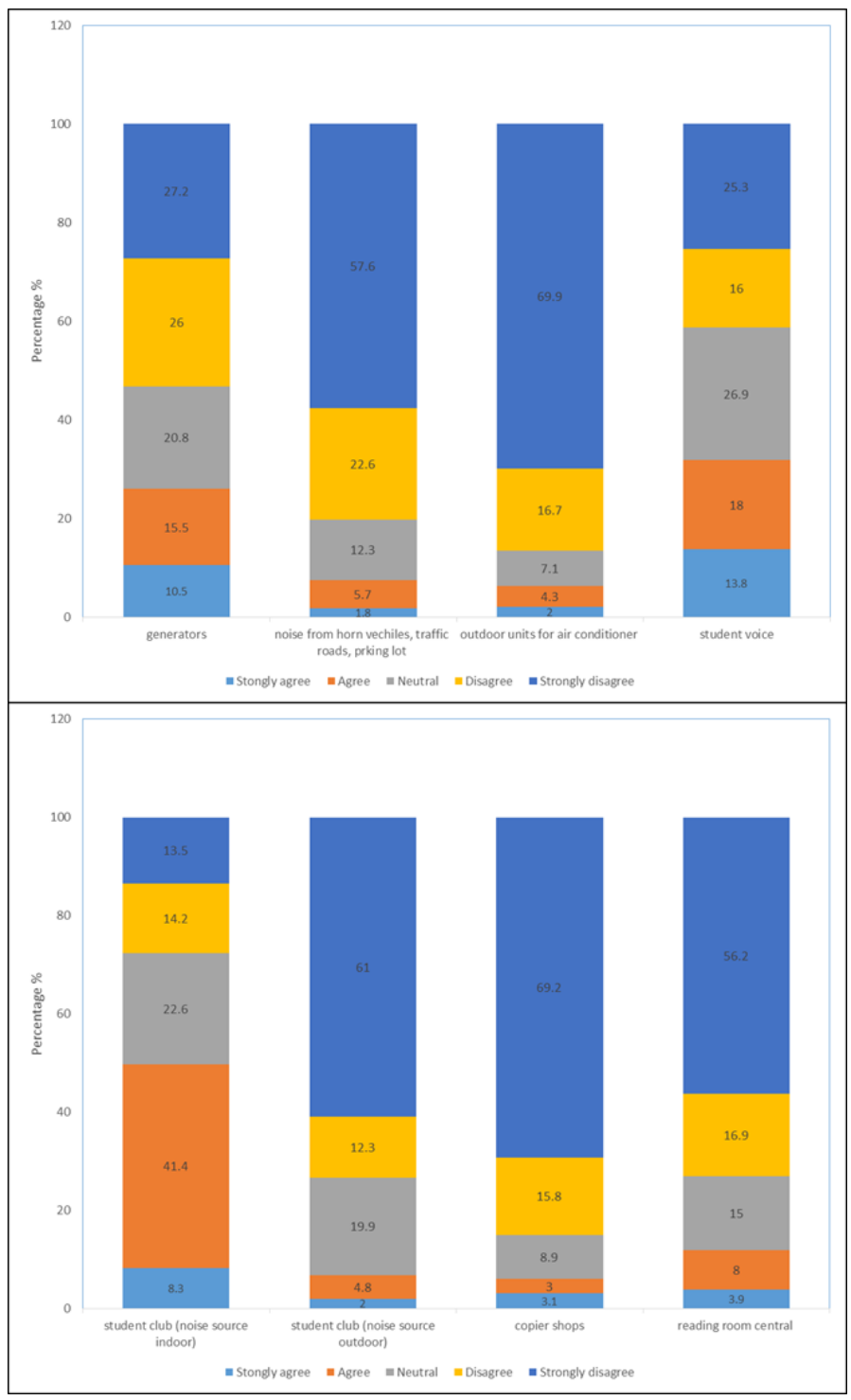

Figure 5: Percentage of students who are affected by the noise sources in the campus.

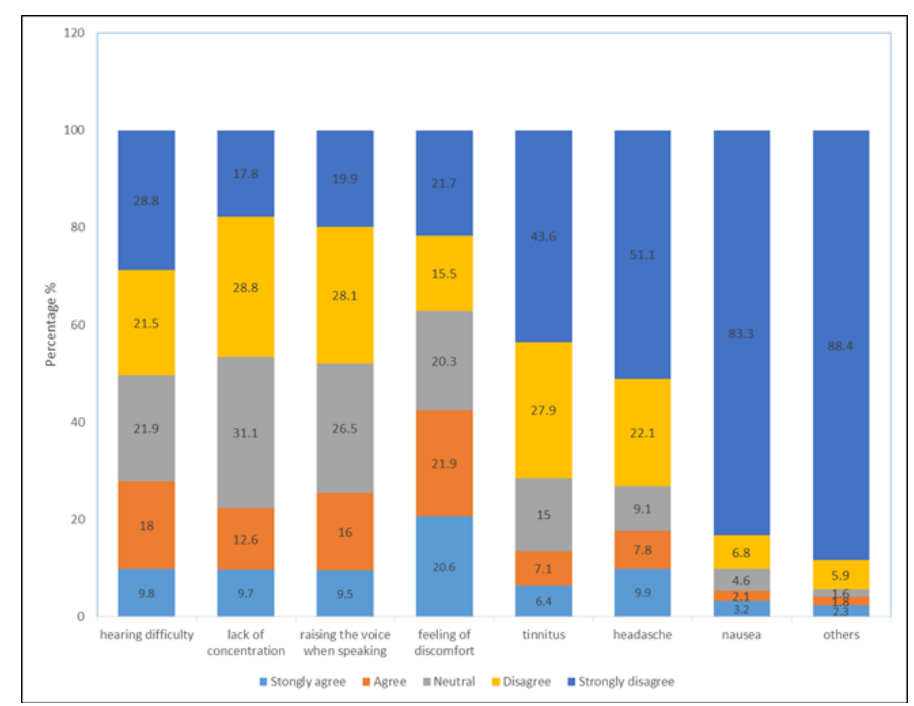

Fig. 6 Percentage complaints of students about the noise effects. 
Table 1 :Questionnaire about noise effects on the students of the Faculty of Engineering

This questionnaire was used to understand the opinions and perceptions of students about noise (sources, levels and effects) during the study day (8 hr. /day) for 5 days/week.

Department:

Noise Sources inside Buildings

\begin{tabular}{|c|c|c|c|c|c|c|}
\hline No & Question & 5 & 4 & 3 & 2 & 1 \\
\hline \multirow[t]{5}{*}{1} & Determine noise sources inside classroom: & & & & & \\
\hline & - $\quad$ air conditioner unit & & & & & \\
\hline & $\begin{array}{ll}- & \text { noise from horn vehicles, traffic roads, parking lot }\end{array}$ & & & & & \\
\hline & $\begin{array}{l}\text { - noise from outside buildings (student voice, generator } \\
\text { noise) }\end{array}$ & & & & & \\
\hline & - $\quad$ others & & & & & \\
\hline \multirow[t]{6}{*}{2} & Determine noise sources inside the laboratories: & & & & & \\
\hline & $\begin{array}{ll}- & \text { specific device ( mention device name) }\end{array}$ & & & & & \\
\hline & $\begin{array}{ll}- & \text { multiple devices work together }\end{array}$ & & & & & \\
\hline & - $\quad$ air conditioner unit & & & & & \\
\hline & $\begin{array}{l}\text { - } \begin{array}{l}\text { noise from outside buildings ( generator noise, student } \\
\text { voice) }\end{array}\end{array}$ & & & & & \\
\hline & - $\quad$ others & & & & & \\
\hline 3 & Are you wearing the hearing protectors inside the labs? & & & & & \\
\hline 4 & $\begin{array}{c}\text { Are occupational health and safety (especially noise) } \\
\text { guidance available within these laboratories? }\end{array}$ & & & & & \\
\hline 5 & $\begin{array}{l}\text { Write the labs name that have high noise ( depends on your } \\
\text { opinion) }\end{array}$ & & & & & \\
\hline
\end{tabular}

Noise Sources in the campus

\begin{tabular}{|c|c|c|c|c|c|c|}
\hline No & Question & 5 & 4 & 3 & 2 & 1 \\
\hline 1 & Determine noise sources in the campus : & & & & & \\
\hline & - $\quad$ generators & & & & & \\
\hline & $\begin{array}{ll}- & \text { outdoor units for air conditioner }\end{array}$ & & & & & \\
\hline & $\begin{array}{ll} & \text { noise from horn vehicles, traffic roads, parking lot }\end{array}$ & & & & & \\
\hline
\end{tabular}



\section{When you expose to noise, are you suffering from any of these effects}

\begin{tabular}{|r|r|r|r|r|r|}
\hline \multicolumn{1}{r|}{$\mathbf{N}$} & Question & & & & \\
\hline $\mathbf{1}$ & Hearing difficulty & & & & \\
\hline $\mathbf{2}$ & Lack of concentration & & & \\
\hline
\end{tabular}




\begin{tabular}{|l|l|l|l|l|l|}
\hline $\mathbf{3}$ & Raising the voice when speaking & & & & \\
\hline $\mathbf{4}$ & Feeling of discomfort & & & & \\
\hline $\mathbf{5}$ & Tinnitus & & & & \\
\hline $\mathbf{6}$ & Headache & & & & \\
\hline $\mathbf{7}$ & Nausea & & & & \\
\hline $\mathbf{8}$ & Others & & & & \\
\hline
\end{tabular}

\section{General Questions}

\begin{tabular}{|c|c|c|c|}
\hline $\mathrm{N}$ & Question & es & 0 \\
\hline 1 & Are you have knowledge about noise and its effects before? & & \\
\hline 2 & How did you know about the noise and its effects? & & \\
\hline & - $\quad$ your study & & \\
\hline & - $\quad$ scientific report (TV, Net) & & \\
\hline & - $\quad$ conference, seminar & & \\
\hline & books, journals..etc. & & \\
\hline 3 & Are you believing that Occupational and Safety health guidance must be available in labs? & & \\
\hline 4 & Are you believing that you must wear the hear protectors during your study in labs? & & \\
\hline 5 & Are you believing that the acoustic insulation must be used in buildings and labs? & & \\
\hline
\end{tabular}

\section{دراسة تأثير الضوضاء على طلبة كلية الهندسة}

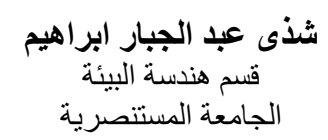

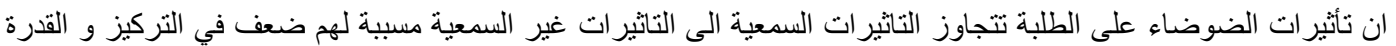

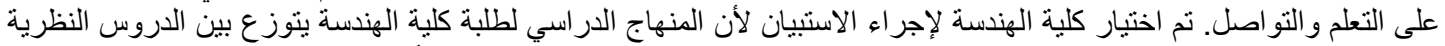



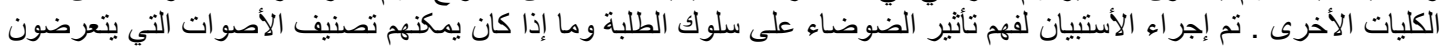

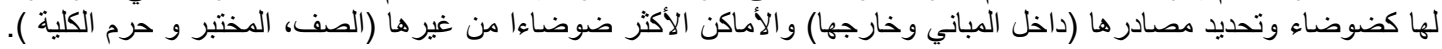

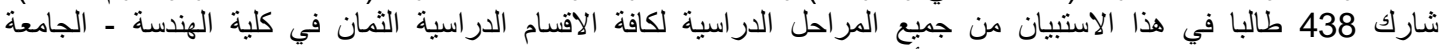



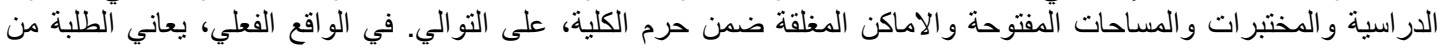

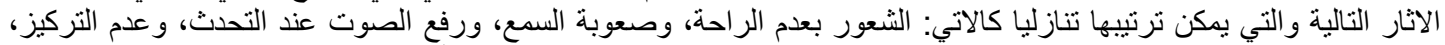



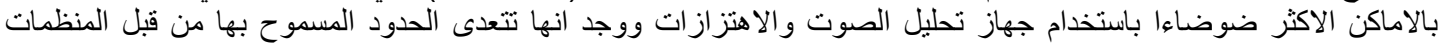

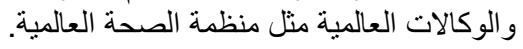

